\title{
Partisan Context and Procedural Values: Attitudes Towards Presidential Secrecy Before and After the 2016 United States Election
}

\author{
Daniel Berliner \\ Associate Professor of Political Science and Public Policy \\ London School of Economics \\ d.berliner@1se.ac.uk
}

Forthcoming, British Journal of Political Science

\begin{abstract}
What shapes attitudes towards procedural rules that constrain executive power? This letter argues that procedural values are contextual: A function of who is in power. Supporters of those in power prefer fewer procedural constraints, while opposition supporters prefer greater. I provide a unique test using data from the 2016 Cooperative Congressional Election Survey. Respondents were asked, in both pre- and post-election waves, if they thought it should be "easier or harder for the President to keep documents secret from the public." The panel design makes it possible to track individual changes following the shift in political context. I find evidence of partisan 'flip' in attitudes following the election, with Republicans becoming less likely - and Democrats more likely - to prefer additional constraints on presidential secrecy. I also find this partisan 'flip' present only among higher political knowledge respondents.
\end{abstract}




\section{Introduction}

What shapes individuals' attitudes towards procedural rules? Procedural rules concern not the outcomes of government decisionmaking but rather the processes by which decisions are made, and include constraints on executive power, bipartisanship, impartiality, and transparency. Public attitudes towards such rules are crucial elements of democratic institutions, particularly when constraints depend not purely on formal rules, but also on informal norms (Schmitter and Karl 1991, Christenson and Kriner 2017, Levitsky and Ziblatt 2018).

This letter argues that such procedural values are fundamentally contextual: A function of which party is in power. Procedural rules have differential consequences for policial parties they create winners and losers. Fewer constraints on executive authority benefit the party that controls the executive, while greater constraints benefit those that do not. Partisanship in turn leads supporters of the party in power to prefer fewer procedural constraints, and opposition supporters to prefer greater constraints. This approach further predicts that when the party in power switches, partisans will also shift their procedural values to match the new political context.

This article offers a unique test of this approach, in the case of American attitudes towards presidential secrecy before and after the November 2016 election, using data from the Cooperative Congressional Election Survey. Respondents were asked, in both pre- and post-election waves, if they thought it should be "easier or harder for the President to keep documents secret from the public." The panel nature of the study enables a stronger test than in previous work, making it possible to track the responses of the same individuals following a real-world shift in political context.

I find evidence of a partisan "flip" in attitudes following the election, with Republicans becoming less likely - and Democrats more likely - to prefer additional constraints on presidential secrecy. Assessing the role of political knowledge, I find the partisan "flip" in attitudes present only among higher-knowledge respondents. In fact, all lower political knowledge respondents shift towards preferring less presidential secrecy, across Republicans, Independents, and Democrats.

To be clear, it was not anticipated that this approach would provide so a powerful a test of the role of political context. I originally planned to leverage evidence from a shift between two 
conditions: An expected - though uncertain - Clinton victory; and a realized Clinton victory. The unexpected (see e.g. CNN 2016) Trump victory yielded, instead, evidence from a much starker shift: Between an expected Clinton victory and a realized Trump victory.

By demonstrating the political logic of procedural attitudes in the case of presidential secrecy, this study suggests both optimistic and pessimistic implications for scholarship on procedural norms. Optimistically, these results suggest that democratic systems can effectively generate their own ever-shifting constituencies for procedural values. More pessimistically, the finding that partisan effects are conditional on political knowledge suggests that the most powerful potential constituency for procedural constraints may be those who are normally least politically engaged. And conversely, that the least consistent support for procedural constraints comes those who are most politically sophisticated, and thus most used to interpreting the political world through partisan information processing.

\section{Partisan Bias and Procedural Values}

Research in American politics has long found public attitudes shaped by partisan considerations (e.g. Campbell et al. 1960, Zaller 1992, Bartels 2002), and recent work has also generally found that such partisan biases are present to a greater degree among those with greater, rather than lower, political knowledge (Taber and Lodge 2006). Gaines et al. (2007, 957) suggest this is because they "more effectively used interpretations to buttress their existing partisan views," while Jerit and Barabas $(2012,672)$ attribute it to both "the supply of information as well as psychological processes." However, some have found the opposite. For example, Anduiza et al. (2013, 1664) find that partisan bias in corruption evaluations in Spain "disappears when political awareness is high."

This study extends this focus beyond attitudes towards factual evaluations and high-profile issues clearly linked to partisan positions, to procedural rules pertaining to the powers of and constraints on the executive. Secrecy is not an issue on which partisanship or ideology offers a clear cue that is consistent across time.

Instead, I argue that attitudes towards secrecy and transparency are crucially shaped by their context-dependent political consequences. Any shift that creates greater transparency or con- 
straints on secrecy will have differential consequences across the political landscape: Greater costs for individuals and groups currently in power, and greater benefits for those in opposition. Limitations on secrecy confront those in power with new risks of unwanted disclosures, adverse media attention, and new constraints on policymaking discretion (Berliner 2014, Berliner et al. Forthcoming). For these reasons, as well as for reasons of perceived policy efficacy and organizational culture, executives and their administrations generally prefer secrecy and resist attempts to reduce or constrain it (Roberts 2006, Pasquier and Villeneuve 2007).

Individuals with partisan attachments - whether psychological, social, or ideological - in turn interpret these consequences through the lens of their partisanship. Procedural rules can either benefit or threaten (Mason 2016) the groups with which partisans identify, depending on which group is in power and thus disproportionately affected.

However, empirical evidence on the role of partisanship in procedural attitudes has been mixed. Reeves and Rogowski $(2015,2016)$ do find partisan differences in support for presidential powers, including executive privilege. Christenson and Kriner (2017) find differences in partisan support for presidential unilateral action depending on whether survey prompts referenced President Bush or President Obama. Others find evidence of partisan effects on procedural values in other contexts (e.g. Goren 2005, Anduiza et al. 2013, Park and Smith 2016, Ahlquist et al. 2018). Yet several other studies find no evidence of partisan effects (e.g. Gibson 2007, Doherty and Wolak 2012, Reeves and Rogowski 2018), even in support for presidential powers in a survey experiment varying the hypothetical identity of the president (Reeves et al. 2017).

One potential explanation for these mixed findings is the difficulty in studying real-world changes of the party in power (and thus which group benefits or is threatened). Existing evidence comes overwhelmingly from either associations in general population surveys at a given point in time, or from the effects of researcher-manipulated vignette treatments in survey experiments. Neither of these, however, can recreate the conditions necessary to fully understand the true effect of interest: What happens to attitudes when national-level political control itself changes. Indeed, Christenson and Kriner (2017, p.341) note that "comparing across presidents... is no easy task." No existing studies on procedural values incorporate such real-world changes in political context, with important exceptions of Smith and Park (2013) who survey a panel of 
respondents before and after intensification of Senate health care debate in 2009-10, and Bartels and Kramon's (2020) study of attitudes towards judicial power in Ghana, using repeated crosssections across presidential elections.

I thus build on this literature by examining changes in procedural attitudes following a major shift in politicial context, similar to Gerber and Huber's (2010) study of economic evaluations, and thus avoiding the "captive audience assumption" (Druckman et al. 2012) of studies using survey-based information treatments.

Previous research on attitudes towards secrecy and transparency has not focused attention on contextual factors that change depending on political configurations. Rather, such studies generally focus on individual and institutional factors that remain largely constant over time. Partisanship and ideology have often emerged as important findings. For example, Piotrowski and Van Ryzin (2007) find several factors associated with citizen demand for government transparency, including political ideology - although in different directions for different dimensions of transparency. Cuillier (2008) finds some evidence that political conservatism is associated with less support for press access to government records. Cuillier and Pinkleton $(2011,227)$ focus on "psychographic factors," including liberalism, in explaining support for government transparency. However, none of these studies are able to disentangle the partisanship of individual respondents from broader political configurations, meaning that findings relating ideology or partisanship with procedural values could be a function of time-bound political context.

In sum, past research offers conflicting expectations. Previous studies of attitudes towards transparency and secrecy suggest leading roles for individual characteristics and constant (rather than context-specific) ideological patterns. Some studies of procedural attitudes have identified partisan biases, yet others have found none. And while many scholars of public opinion have found that political knowledge accentuates, rather than dampens, partisan biases, few have extended this to attitudes towards procedural values, and one study of attitudes towards responsibility for corruption even found the reverse. 


\section{Data and Model}

The data in this study comes from Arizona State University Team Module (Hoekstra 2019) of the 2016 Cooperative Congressional Election Survey, an online panel survey conducted by YouGov before and after the election (Ansolabehere and Schaffner 2016). The pre-election surveys for this module were in the field from September 28, 2016 to November 3, 2016, and the post-election surveys were in the field from November 9, 2016 to December 12, 2016. This study's questions were asked in a module of 1,000 respondents. Of these, 789 took the postelection survey and responded to the outcome question in both rounds.

To measure support for constraints on presidential secrecy, respondents were presented with the following prompt, and a visual scale running from "Much harder" to "Much easier":

"Do you think it should be easier or harder for the President to keep documents secret from the public? Please choose a point along the scale."

The direction of this scale has been flipped in this analysis, for ease of interpretation, such that a value of 0 represents "much easier" and 100 "much harder." Higher values of this scale reflect greater demand for constraints on secrecy and thus greater transparency. Respondents answered this question twice, once in the pre-election wave and once in the post-election wave.

Several points are worthy of note. First, the question uses simple language to explicitly assess views toward constraints on presidential power - whether secrecy should be more or less constrained. Second, the wording of this question sidesteps potential knowledge differences of the precise status quo policy on presidential secrecy, instead capturing only preferred changes. This approach is similar to studies of thermostatic public opinion, capturing responses "anchored to the actual (or perceived) level of current spending, the policy status quo" (Wlezien 1995, 984).

Third, the timing of the post-election wave is also important, in terms of what had not yet taken place. Trump had not yet taken office and so was not yet actually President. There were not yet any top-down political party cues regarding constraints on secrecy, that might offer heuristics how to respond. Finally, elite opinion among Republicans had not yet consolidated around support for the soon-to-be President, with many Republican public figures still expressing high- 
profile concerns. All of these factors would lead a priori expectations to tend against a strong partisan shift in attitudes towards constraints on presidential secrecy.

While the average response shifted only slightly (see Appendix) from the first to the second wave, this masks substantial heterogeneity as different individuals shifted in different directions. The within-individual correlation between pre-election and post-election responses is only 0.29. A full 64 percent of respondents shifted by ten or more points in either direction, and 32.6 percent crossed the midpoint in one direction or the other - either from below 50 to above, or vice versa.

I measure the outcome variable in three ways: First, a dichotomous indicator of whether respondents shifted towards preferring greater constraints on secrecy. Second, a more restrictive indicator for only those respondents shifting ten or more points in that direction. Finally, I use a continuous measure of the raw within-individual changes. Given the complexity of the outcome variable, consistency across these approaches ensures the results are not dependent on one measure. By only modelling within-individual changes, these approaches automatically difference out any individual-specific omitted variables that might be correlated with either initial or post-election attitudes in levels. However, control variables are also included in some models, to ensure that the effect of partisanship on within-individual changes is not confounded by some other factor.

I measure partisanship by aggregating respondents' pre-election seven-point party identification into Republicans, Independents, and Democrats, coding 'leaners' as partisans. Primary models omit Independents in order to directly compare Republicans to Democrats, although this choice is varied in robustness checks along with alternate measures of partisanship, or vote intention. I measure political knowledge using the number of eight items respondents could correctly answer, pertaining to party control of the House, Senate, state legislative houses, their governor, Senators, and Representative. Some models include controls for gender, age, race (dummy variable for white), military family (if respondent or any family member currently or ever served), education ( 0 to 5 scale), and income (0 to 1 scale with separate dummy for non-response).

Both logistic and linear regressions are estimated using the survey package in $\mathrm{R}$, employ module survey weights, and cluster standard errors by state. ${ }^{1}$

\footnotetext{
${ }^{1}$ The single respondent from Vermont was dropped to enable clustering by state.
} 


\section{Results}

Figure 1 shows the average within-person change in support for constraints on presidential secrecy (with survey weights), separately by partisanship, giving an initial indication of large partisan effects. The first panel shows that Democrats shifted to prefer greater constraints on presidential secrecy, Republicans to prefer fewer, and Independents shifted more similarly to Democrats. The second and third panels repeat this in sub-samples split at the mean political knowledge. Even this illustration of the raw responses makes the main findings starkly clear: The partisan "flip" takes place only among high political knowledge individuals. I next proceed to model these shifts in order to confirm that they are statistically meaningful and not an artifact of some other factor.

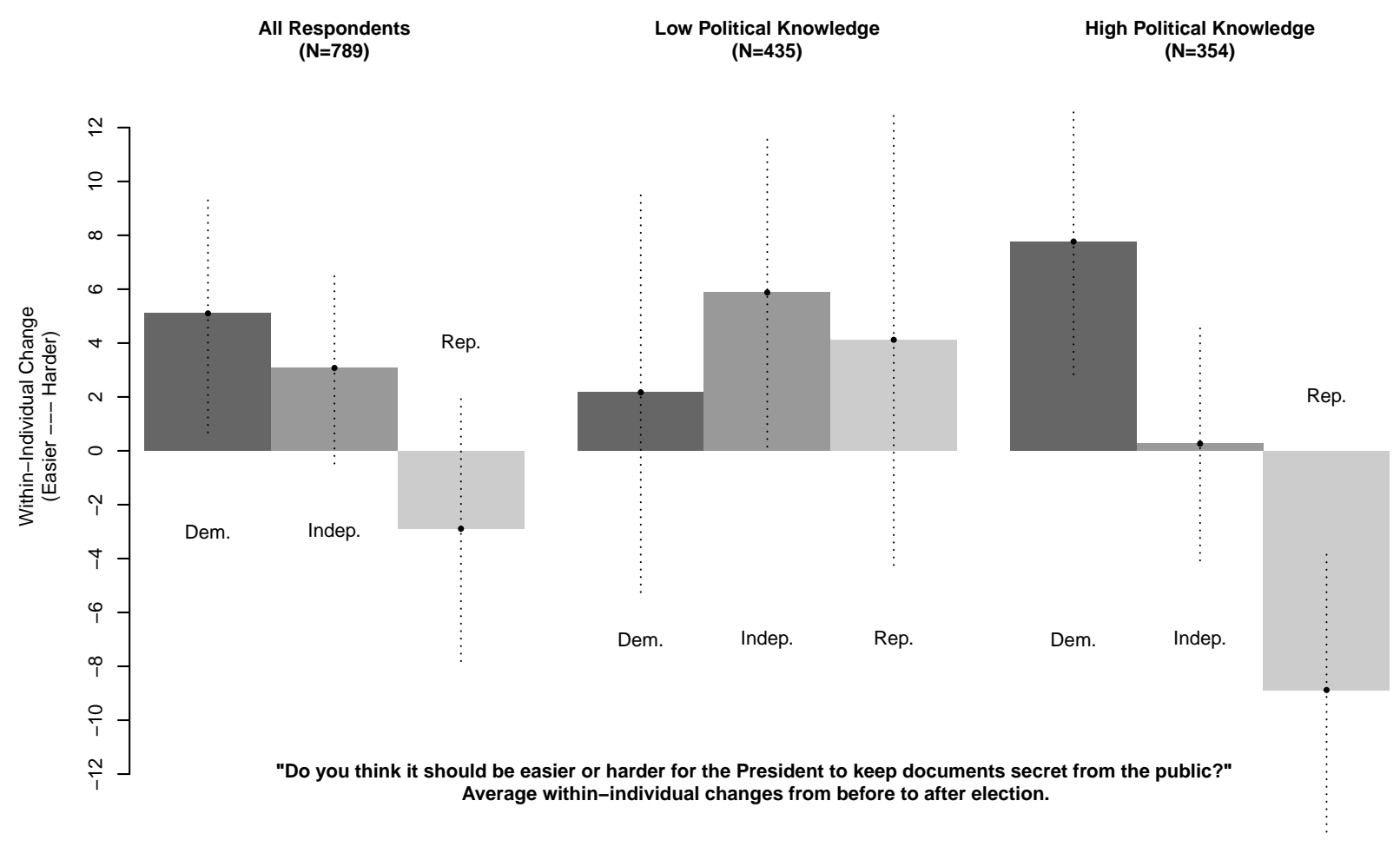

Figure 1: Average within-person changes in support for constraints on presidential secrecy (100-point scale), moving from the pre-election survey wave to the post-election survey wave, for all individual, individuals below mean political knowledge, and above. Dotted lines show 90\% confidence intervals.

Results (Table 1) confirm a large and statistically significant 'partisan flip' in attitudes. Republicans are less likely (and Democrats more likely) to shift attitudes in the direction of preferring greater constraints on presidential secrecy. These findings hold with or without control 
variables, and using either the less or more restrictive outcome indicator. Modeling the raw change in response shows that Republicans shift on average 9.28 points more than Democrats in the direction of preferring fewer constraints on secrecy after the election.

Results including interaction terms between partisanship and political knowledge find significant interactive effects, with larger partisan effects among those with greater political knowledge. Figure A2 in the Appendix shows marginal effects plots of these results, demonstrating that the differences in individual changes in attitudes across Republicans and Democrats are statistically insignificant at low levels of knowledge, but significant and very substantial at high levels. Among the most politically knowledgeable, the probability of a shift in attitudes towards greater constraints on secrecy is 0.35 lower for Republicans than for Democrats; while the average within-individual shift in raw score is 19.4 further in a negative direction for Republicans than for Democrats. This finding suggests that such individuals more readily link questions such as these to their anticipated political consequences - either because they are more aware of such consequences, or care more about them.

Additional results in the Appendix demonstrate the main findings' robustness. The main results of interest are highly similar across models employing alternate measures in place of partisanship, additional control variables, and inclusion of independents in the sample. No other interaction term with partisanship is significant, aside from an alternate proxy for political sophistication. Finally, as identification depends on the assumption that no other event aside from the shift in presidential partisan context affected partisan attitudes over this period, I employ a placebo test measuring changing attitudes towards secrecy by state governors, rather than the President. Partisanship is insignificant in explaining changing attitudes towards gubernatorial secrecy, emphasizing the prime role played by the change in national party-of-the-president. 


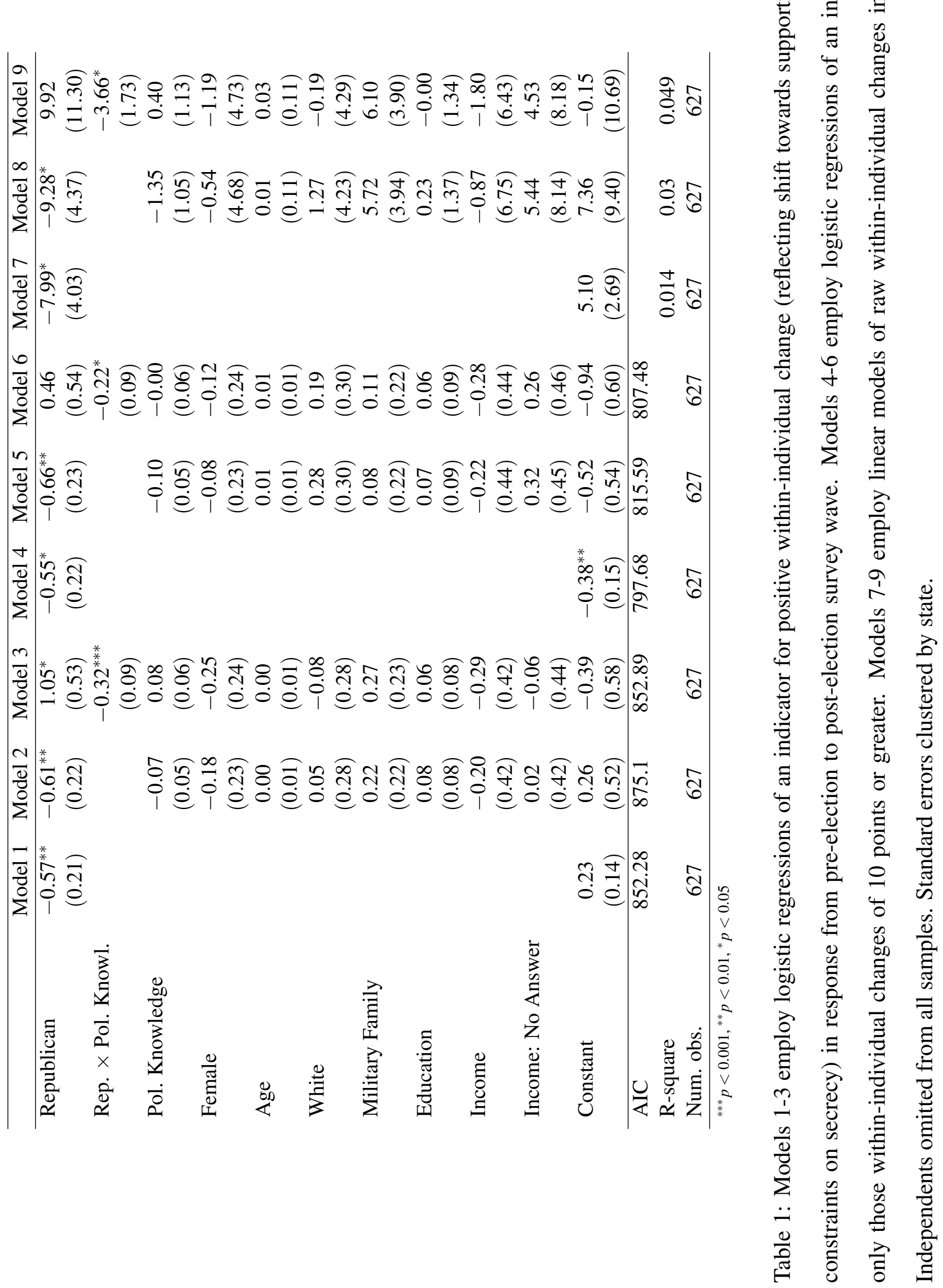




\section{Conclusion}

Recent political developments have renewed concerns over the sources and survival of both formal and informal democratic norms (e.g. Nyhan 2017, Levitsky and Ziblatt 2018). Whereas formal rules may be inscribed in constitutions and laws, informal norms depend also on the values of both elites and, potentially, mass publics. This makes public attitudes towards procedural rules a highly relevant topic for contemporary study. Many democratic norms pertain to procedural values, such as values over participation, deliberation, checks and balances, and bipartisanship. Transparency and secrecy, the focus of this study, are similar: pertaining to decisionmaking processes rather than outcomes.

A long tradition of research sees potential for the logic of partisan competition itself to lead to such procedural rules, including constraints in the House of Representatives (Binder 1996), new accontability and oversight institutions (Grzymala-Busse 2006), and the adoption of transparency laws (Berliner and Erlich 2015, Michener 2015). All these procedural values create differential consequences across political configurations: They are constraining and costly for those in power, and offer protection and potential benefits for those out of power. Transparency not only constrains but also creates new risks of adverse media attention for those in power; risks which greater secrecy can ameliorate.

It is precisely these consequences that have been used to argue that democratic norms can originate in, and draw sustenance from, the 'enlightened self-interest' of partisan actors who recognize the wisdom in trading short-term and particularistic constraints for long-term and broadly-shared benefits. Yet there is no guarantee that this will always be the case. The very

political logic suggests that the strongest constituency for upholding such norms will always lie precisely where actual political power to do so is weakest.

This study finds this driving role of political context extending beyond political elites themselves, to the public at large. The power of partisanship (Bartels 2002, Huddy et al. 2015) is such that individuals shift their attitudes towards constraints on presidential secrecy depending on their political alignment with the current President and party in power. However, these shifts are strongest among more politically sophisticated respondents. This finding suggests stark limits to how 'enlightened self-interest' might yield partisan restraint among mass publics. 
Of course, the findings here may not generalize to a more "ordinary" political transition, particularly with a more conventional Republican candidate. While this study cannot evaluate this possibility with certainty, there are also reasons to expect political effects to be even stronger, not weaker, in more ordinary circumstances where partisans are more internally unified. Similarly, as this study's primary outcome variable of interest pertains only to secrecy and transparency, not to other procedural values, it remains a possibility that these results may not generalize further. However, this setting also offers a particularly hard test of the partisan bias hypothesis, as secrecy is a more obscure issue than other, more high-profile values that have received greater scholarly attention. Additionally, the question wording in this study asks respondents not about support for the exercise of presidential power itself, but rather for constraints on it. Future research should further extend investigation of attitudes towards different procedural rules across multiple settings. 


\section{Supplementary Material}

Data and replication files are available in Harvard Dataverse at:

$<$ https://doi.org/10.7910/DVN/WJPSJ2> and online appendices are available at: TBA.

\section{Acknowledgments}

The author thanks Valerie Hoekstra, Cameron Thies, and the Arizona State University School of Politics and Global Studies, for making possible the ASU CCES module. For feedback on earlier versions of this project, thanks to Mark Ramirez, Sara Hobolt, Thomas Leeper, Joachim Wehner, Milli Lake, and participants in panels or presentations at the 2017 CCES Conference, the University College London Department of Political Science Research Seminar, the Rutgers University School of Public Affairs and Administration Research Colloquium, and the 2018 APSA Annual Meeting. 


\section{References}

Ahlquist, John, Nahomi Ichino, Jason Wittenberg, and Daniel Ziblatt. 2018. "How Do Voters Perceive Changes to the Rules of the Game? Evidence from the 2014 Hungarian Elections." Journal of Comparative Economics.

Anduiza, Eva, Aina Gallego, and Jordi Munoz. 2013. "Turning a blind eye: Experimental evidence of partisan bias in attitudes toward corruption." Comparative Political Studies 46(12): 1664-1692.

Ansolabehere, Stephen and Brian Schaffner. 2017. COOPERATIVE CONGRESSIONAL ELECTION STUDY, 2016: COMMON CONTENT. Harvard University.

Bartels, Larry. 2002. "Beyond the running tally: Partisan bias in political perceptions." Political Behavior 24(2): 117-150.

Bartels, Brandon L., and Eric Kramon. 2020. "Does Public Support for Judicial Power Depend on Who is in Political Power? Testing a Theory of Partisan Alignment in Africa." American Political Science Review 114(1): 144-163.

Berliner, Daniel. 2014. "The political origins of transparency." The Journal of Politics 76(2): 479-491.

Berliner, Daniel. 2020. "Replication Data for: Partisan Context and Procedural Values: Attitudes Towards Presidential Secrecy Before and After the 2016 United States Election." <https://doi.org/10.7910/DVN/WJPSJ2>, Harvard Dataverse, V1, UNF:6:nsQjxRicS+wfMORPnjr10Q== [fileUNF].

Berliner, Daniel, and Aaron Erlich. 2015. "Competing for transparency: Political competition and institutional reform in Mexican states." American Political Science Review 109(1): 110-128. 
Berliner, Daniel, Benjamin Bagozzi, Brian Palmer-Rubin, and Aaron Erlich. Forthcoming. "The Political Logic of Government Disclosure: Evidence from Information Requests in Mexico." The Journal of Politics DOI:10.1086/709148.

Binder, Sarah. 1996. "The partisan basis of procedural choice: allocating parliamentary rights in the House, 1789-1990.” American Political Science Review 90(1): 8-20.

Campbell, Angus, Philip Converse, Warren Miller, and Donald Stokes. 1960. The American Voter. New York: John Wiley \& Sons.

Christenson, Dino, and Douglas Kriner. 2017. "Constitutional qualms or politics as usual? The factors shaping public support for unilateral action." American Journal of Political Science. 61(2): 335-349.

CNN. 2016. “CNN/ORC International Poll, October 25, 2016.” Available at: http://i2.cdn. turner.com/cnn/2016/images/10/25/rel19b.-.election.outcome.pdf.

Cuillier, David. 2008. "Access attitudes: A social learning approach to examining community engagement and support for press access to government records." Journalism \& Mass Communication Quarterly. 85(3): 549-576.

Cuillier, David, and Bruce Pinkleton. 2011. "Suspicion and secrecy: Political attitudes and their relationship to support for freedom of information." Communication Law and Policy 16(3): 227-254.

Doherty, David, and Jennifer Wolak. 2012. "When do the ends justify the means? Evaluating procedural fairness." Political Behavior 34(2): 301-323. 
Druckman, James, Jordan Fein, and Thomas Leeper. 2012. "A source of bias in public opinion stability." American Political Science Review 106(2): 430-454.

Gerber, Alan, and Gregory Huber. 2010. "Partisanship, political control, and economic assessments.” American Journal of Political Science. 54(1: 153-173.

Gibson, James. 2007. "The legitimacy of the US Supreme Court in a polarized polity." Journal of Empirical Legal Studies. 4(3): 507-538.

Goren, Paul. 2005. "Party identification and core political values." American Journal of Political Science 49(4): 881-896.

Grzymala-Busse, Anna. 2006. "The discreet charm of formal institutions: Postcommunist party competition and state oversight." Comparative Political Studies 39(3): 271-300.

Hoekstra, Valerie. 2019.“CCES 2016, Team Module of Arizona State University (ASU).” $<$ https://doi.org/10.7910/DVN/YUONNU>, Harvard Dataverse.

Huddy, Leonie, Lilliana Mason, and Lene Aarøe. 2015. "Expressive partisanship: Campaign involvement, political emotion, and partisan identity." American Political Science Review. 109(1): $1-17$.

Jerit, Jennifer, and Jason Barabas. 2012. "Partisan perceptual bias and the information environment." The Journal of Politics. 74(3: 672-684.

Levitsky, Steven, and Daniel Ziblatt. 2018. How Democracies Die. Crown.

Mason, Lilliana. 2016. "A cross-cutting calm: How social sorting drives affective polarization.” Public Opinion Quarterly. 80(S1): 351-377. 
Michener, Gregory. 2015. "How cabinet size and legislative control shape the strength of transparency laws." Governance, 28(1):77-94.

Nyhan, Brendan. 2017. “Norms Matter.” Politico Magazine. <https://www.politico.com/ magazine/story/2017/09/05/why-norms-matter-politics-trump-215535>

Pasquier, Martial, and Jean-Patrick Villeneuve. 2007. "Organizational barriers to transparency: A typology and analysis of organizational behaviour tending to prevent or restrict access to information.” International Review of Administrative Sciences 73(1): 147-162.

Park, Hong Min, and Steven Smith. 2016. "Partisanship, Sophistication, and Public Attitudes about Majority Rule and Minority Rights in Congress." Legislative Studies Quarterly 41(4): 841-871.

Piotrowski, Suzanne, and Gregg Van Ryzin. 2007. "Citizen attitudes toward transparency in local government." The American Review of Public Administration 37(3): 306-323.

Reeves, Andrew, and Jon Rogowski. 2015. "Public opinion toward presidential power." Presidential Studies Quarterly 45(4): 742-759.

Reeves, Andrew, and Jon Rogowski. 2016. "Unilateral Powers, Public Opinion, and the Presidency." The Journal of Politics. 78(1): 137-151.

Reeves, Andrew, and Jon Rogowski. 2018. "The Public Cost of Unilateral Action.” American Journal of Political Science.

Reeves, Andrew, Jon Rogowski, Min Hee Seo, and Andrew Stone. 2017. "The contextual determinants of support for unilateral action.” Presidential Studies Quarterly 47(3): 448-470. 
Roberts, Alasdair. 2006. Blacked out: Government secrecy in the information age. Cambridge University Press.

Schmitter, Philippe, and Terry Lynn Karl. 1991. "What Democracy Is.. and Is Not." Journal of Democracy, 2(3): 75-88.

Smith, Steven, and Hong Min Park. 2013. “Americans' attitudes about the senate filibuster." American Politics Research 41(5): 735-760.

Taber, Charles, and Milton Lodge. 2006. "Motivated skepticism in the evaluation of political beliefs.” American Journal of Political Science 50(3): 755-769.

Wlezien, Christopher. 1995. "The public as thermostat: Dynamics of preferences for spending." American Journal of Political Science. 39(4): 981-1000.

Zaller, John R. 1992. The Nature and Origins of Mass Opinion. New York: Cambridge University Press. 


\section{Online Appendix}

Online Appendix for: Berliner, Daniel. Forthcoming. "Partisan Context and Procedural Values: Attitudes Towards Presidential Secrecy Before and After the 2016 United States Election." British Journal of Political Science. 


\section{Figures}

Before Election

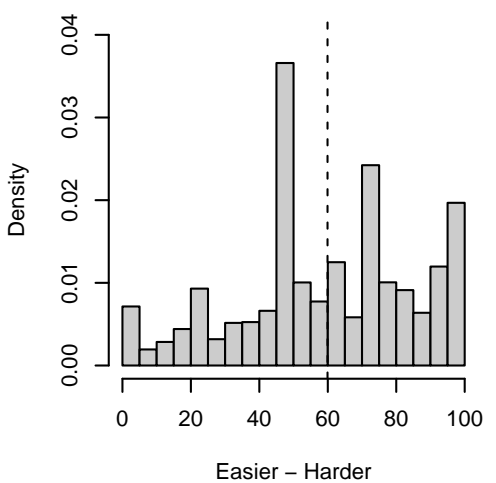

After Election

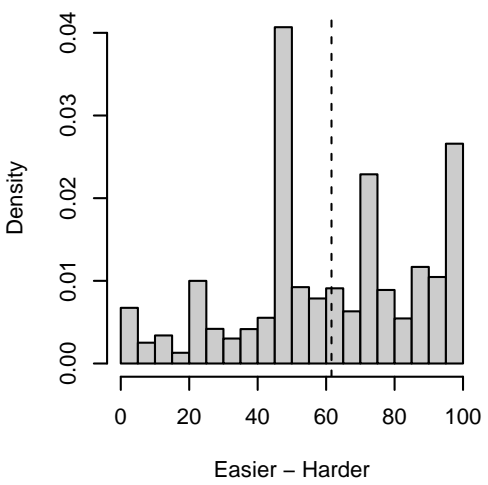

Change from Before to After

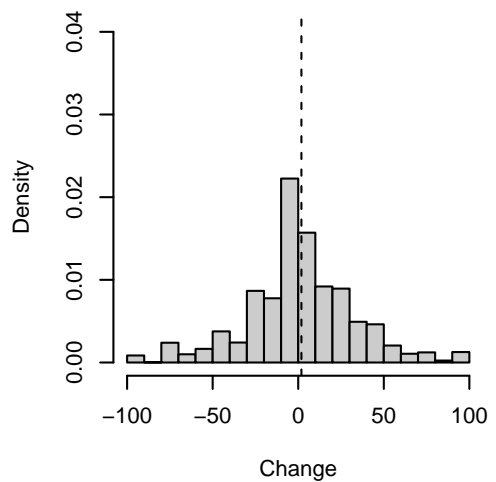

Figure A1: Three histograms showing the distribution of support for constraints on presidential secrecy, in the pre-election and post-election survey waves, and of individual changes. A positive change reflects a shift towards supporting greater constraints on secrecy. All three based on the 789 respondents that took both survey waves and answered both questions. Dashed line indicates the mean value.

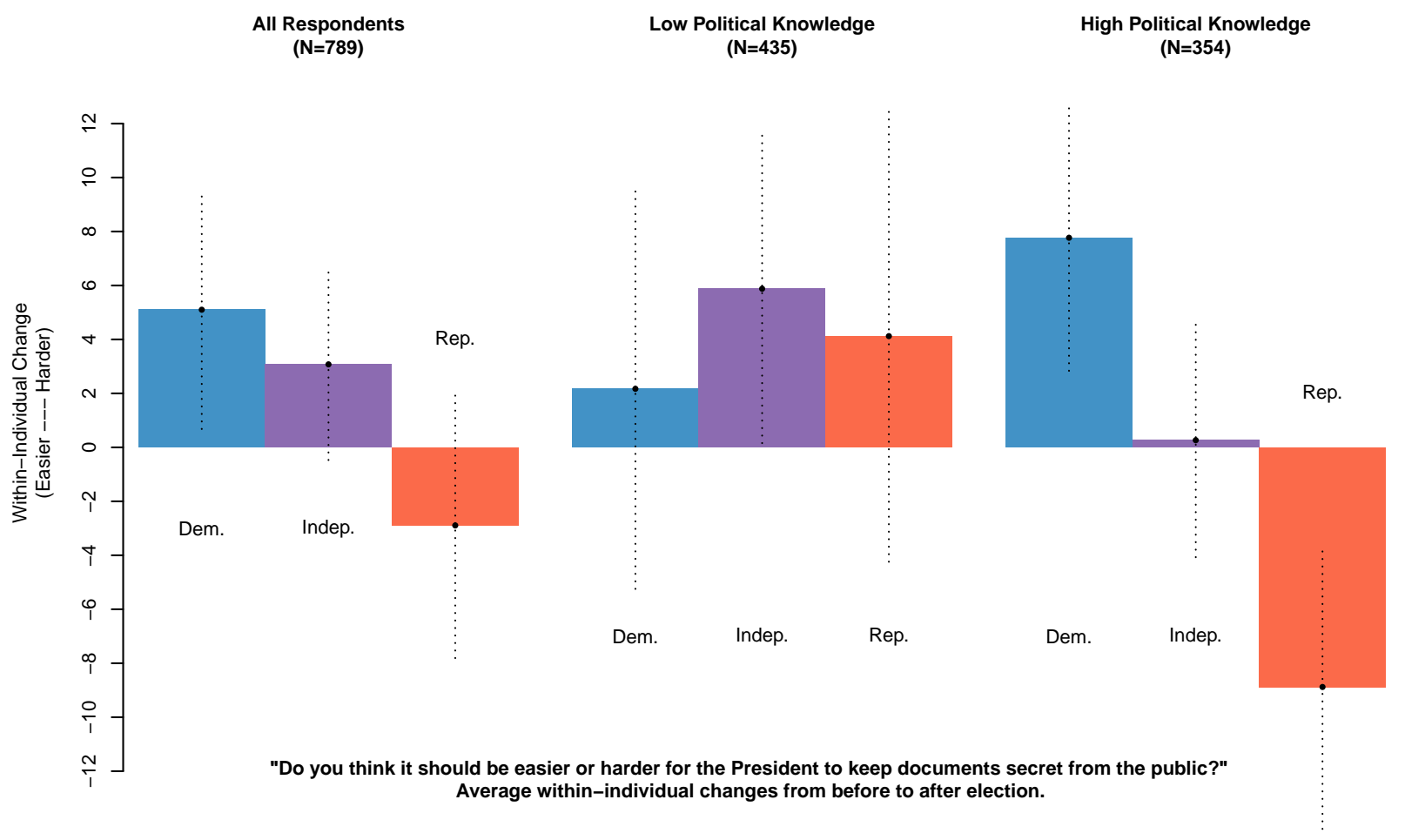

Figure A2: Color version of main manuscript Figure 1. Average within-person changes in support for constraints on presidential secrecy (100-point scale), moving from the pre-election survey wave to the post-election survey wave, for all individual, individuals below mean political knowledge, and above. Dotted lines show $90 \%$ confidence intervals. 

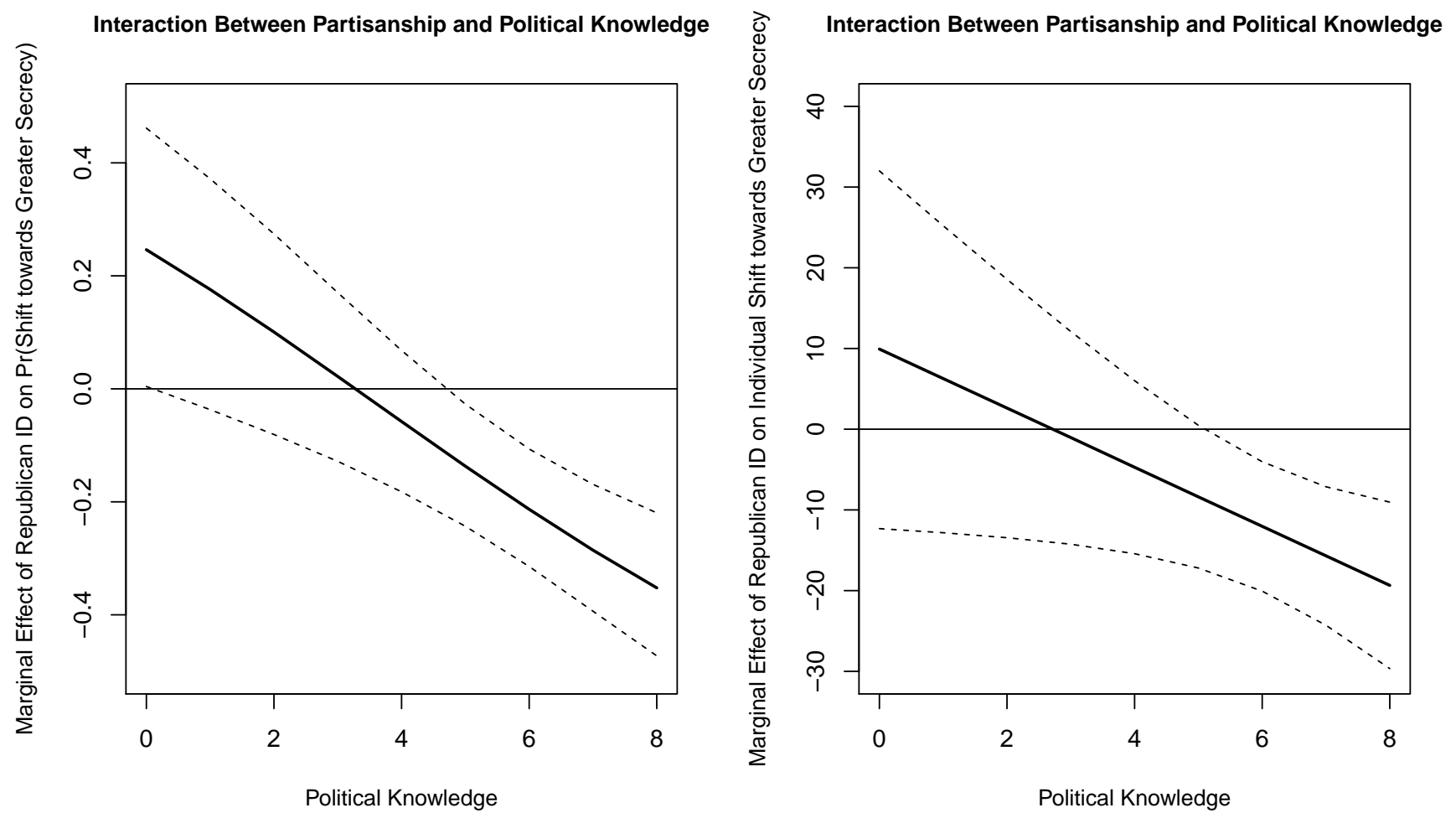

Figure A3: Marginal effects of Republican partisan identification at varying levels of political knowledge, based on simulations from results of Models 3 and 9 in Table 1 in the main paper. Dashed lines indicate 95 percent confidence interval. 


\section{Robustness Checks}

Table A3 presents models replacing the measure of partisan identification with an indicator for Trump vote, either reported vote intention in pre-election survey, or reported vote choice in postelection survey. Results are highly similar both for the main models and the interaction terms with political knowledge.

Table A4 retains Independents in the sample (which were omitted from the sample in the main results), comparing either Republicans to the set of Democrats and Independents, or Democrats to the set of Republicans and Independents. Results are highly similar to the main results.

Table A5 includes additional control variables to test for alternative explanations of the results. In case the results were an artifact of varying initial attitudes towards transparency across partisan groupos, Models 1-3 control for an index of principled support for transparency. This is an additive index of six questions, asked prior to the outcome variable question. These questions assess both support for transparency and tradeoffs between transparency and competing values like secrecy and national security. Respondents chose from a 5-point Likert scale for each of the following statements. Responses to the latter three were subsequently flipped so that higher values for each represents greater value for a principle of transparency.

- Citizens have a right to get the information they want from the government.

- More information about what the government does would help me make better decisions about how to vote.

- More information about what the government does would help fight corruption.

- It is important for the government to keep some information secret to protect national security.

- It is important for the government to keep some information secret to protect the privacy of other citizens.

- Answering citizens' requests for information is a waste of the government's time and resources.

The transparency index has no effect on the outcome variable and does not substantively change the main results. 
Another alternate explanation for this paper's main findings might be simple reversion to the mean, as individuals with extreme positions on the scale of attitudes towards presidential secrecy simply tend to adopt less extreme positions at a later point in time. To address this possibility, I include a robustness check controlling for the initial response in the pre-election survey wave (Models 4-6 in Table A4). However, as these initial responses already capture a substantial element of partisanship, this is a difficult test. Although the effects are more uncertain and smaller in magnitude, all remain in the expected direction and some are statistically significant.

Although it is difficult to envision, one might argue that the changes in attitudes towards Presidential secrecy might be due to some other change that took place in between survey waves, unrelated to the Presidential election itself. To address this possibility, I can control for responses to an additional question that posed an identical prompt about keeping documents secret, but pertaining to the governor of the respondent's state rather than to the President. By controlling for changes in this response (Models 7-9 in Table A5), I capture any broader shifts in attitudes towards secrecy - distinct from the presidency - that may have taken place in the intervening period. (The two change variables are correlated at only 0.53.) The main results of interest remain very similar, even though the coefficient on Governor Secrecy Change is also large and significant.

Table A6 shows alternative interaction terms between partisanship and other variables. The first of these (Model 1) is an alternative measurement approach to political knowledge, using an indicator of high reported interest in following the news, in place of the index of factual items correctly answered. The results are highly similar. The remaining models in Table A6 assess a potential concern that some other factor might be more relevant than political knowledge in explaining variation in the 'partisan flip' in attitudes. However, no other interaction terms are identified as statistically significant, confirming the importance of political knowledge.

Table A7 employs an alternate measure of partisanship, using the seven-point partisan identification scale itself in place of an indicator for Republicans (or Democrats, as in Table A4). Results remain highly similar. Models 7 and 8 in this table estimate specific categorical effects for each level of the seven-point scale. This reveals surprisingly large effects (in the hypothesized directions) for weak partisans (Lean Republican and Lean Democrat), yet smaller effects for strong partisans.

Finally, Table A8 shows a placebo test using the change in attitudes towards gubernatorial 
secrecy as an alternative outcome variable. This further helps to assess an alternative explanation that some other change over the intervening period is responsible for the main results. Models 1-3 include all respondents, while Models 4-6 exclude respondents form the twelve states with gubernatorial elections in 2016. In all cases, partisanship plays no significant role in explaining variation in attitudes towards gubernatorial secrecy, emphasizing the prime role played by the change in national party-of-the-president. 


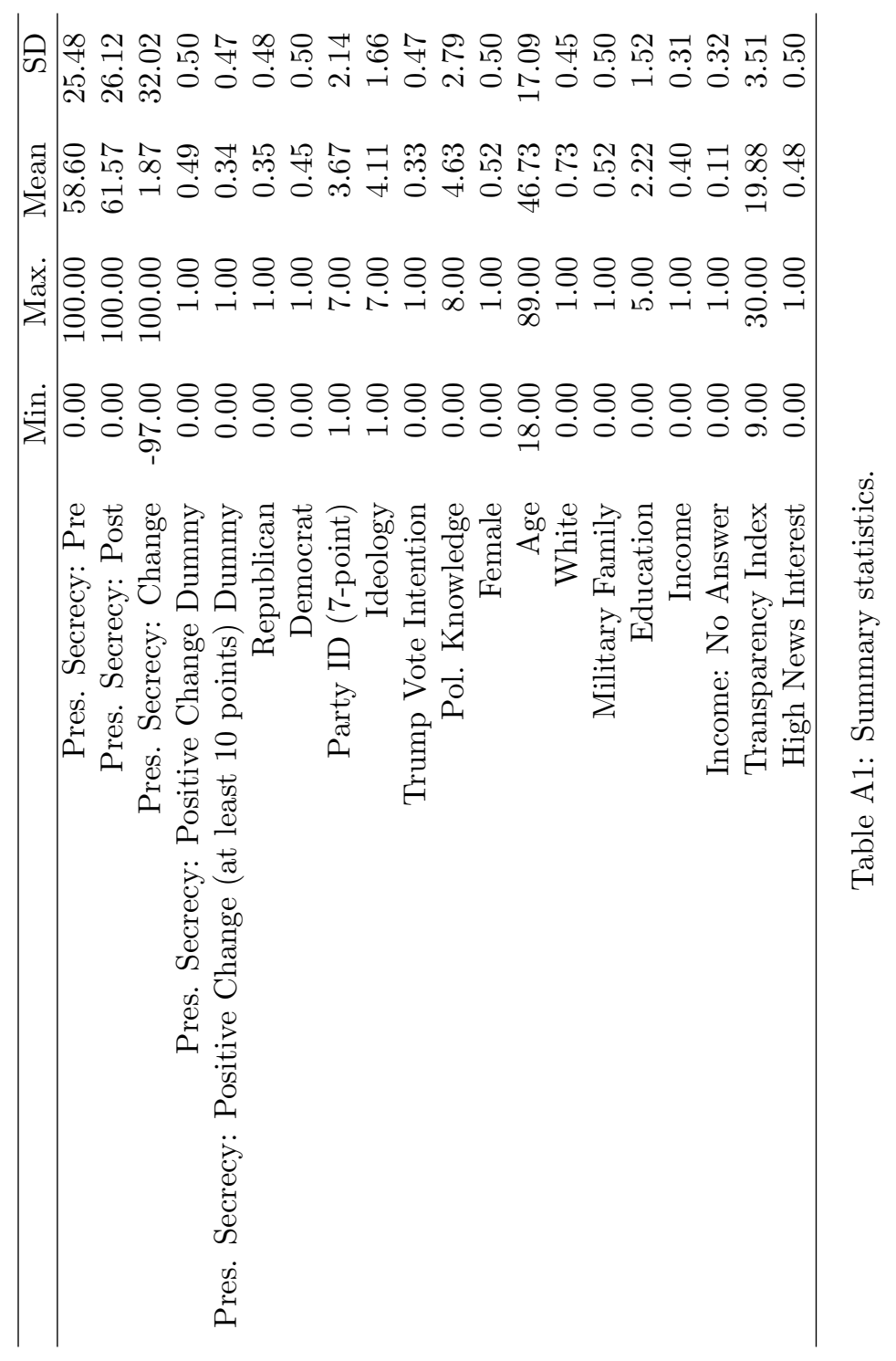

$\frac{\frac{\theta}{0}}{\frac{\sigma}{H}}$ 


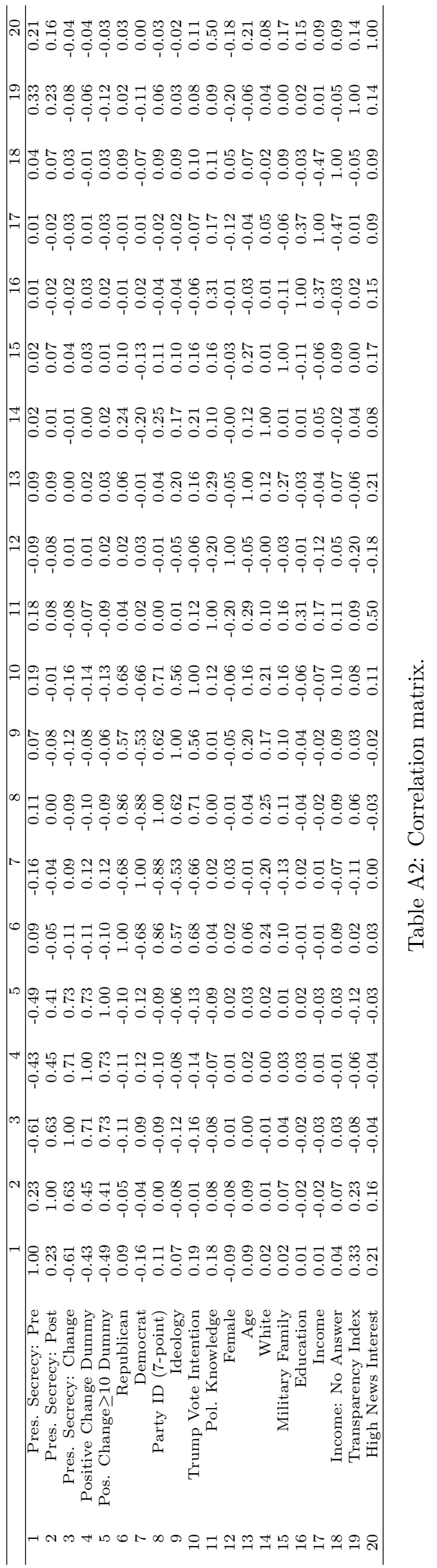




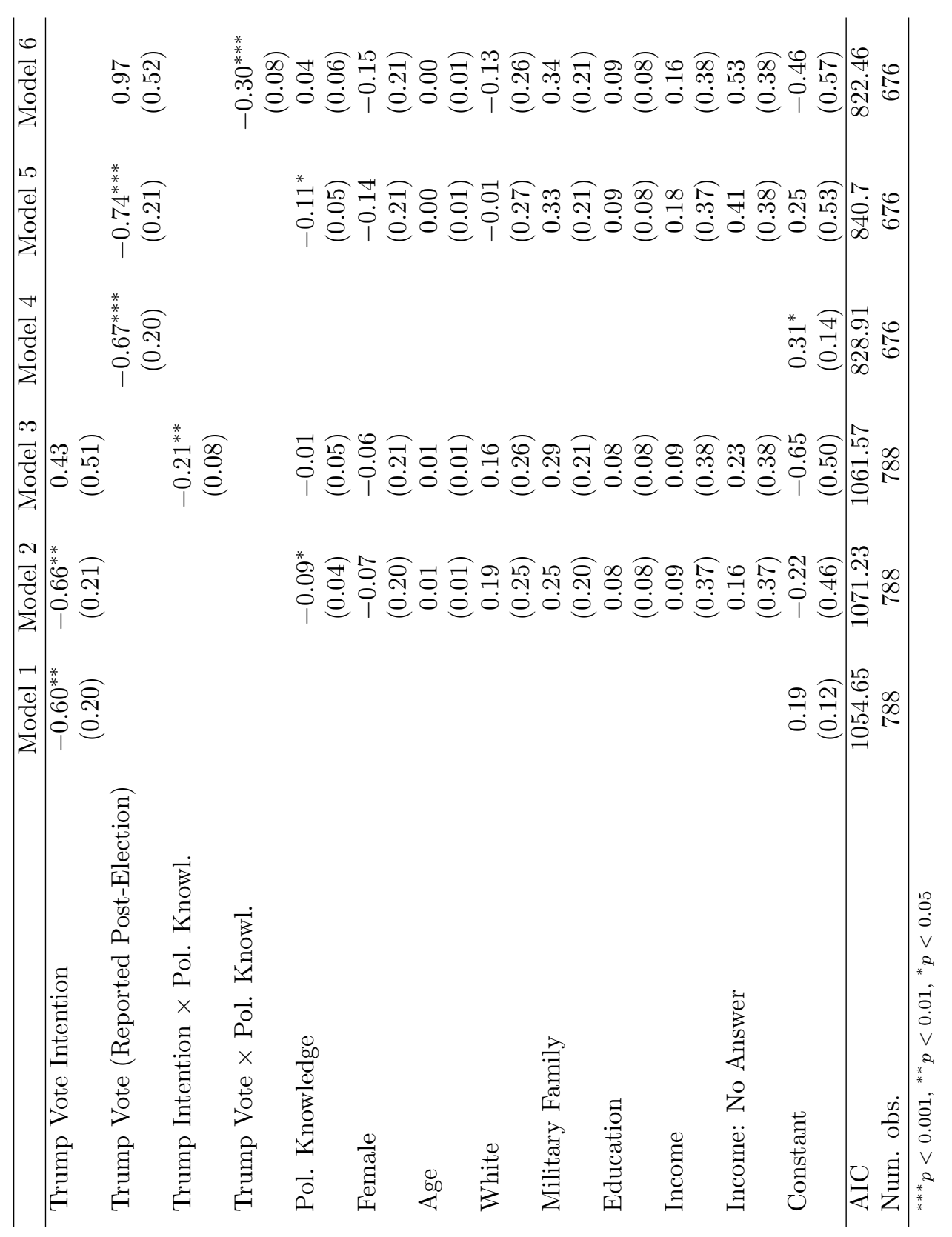

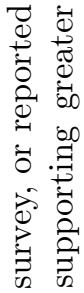

유 응

过

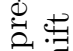

$\exists$ \%

च

.월

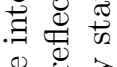

응

范

늉

언 त्ञ

它

렁 룽

o

过. 毒

范落

总㻤

牙落

药

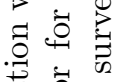

苋.

:

엄

द्व

as a

눈 웅

a. 0

प4 50.0

品

శึ.

द्व

b등

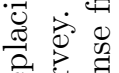

원

究

검

w

范

요몌

兽. 苛

㻤

需递 


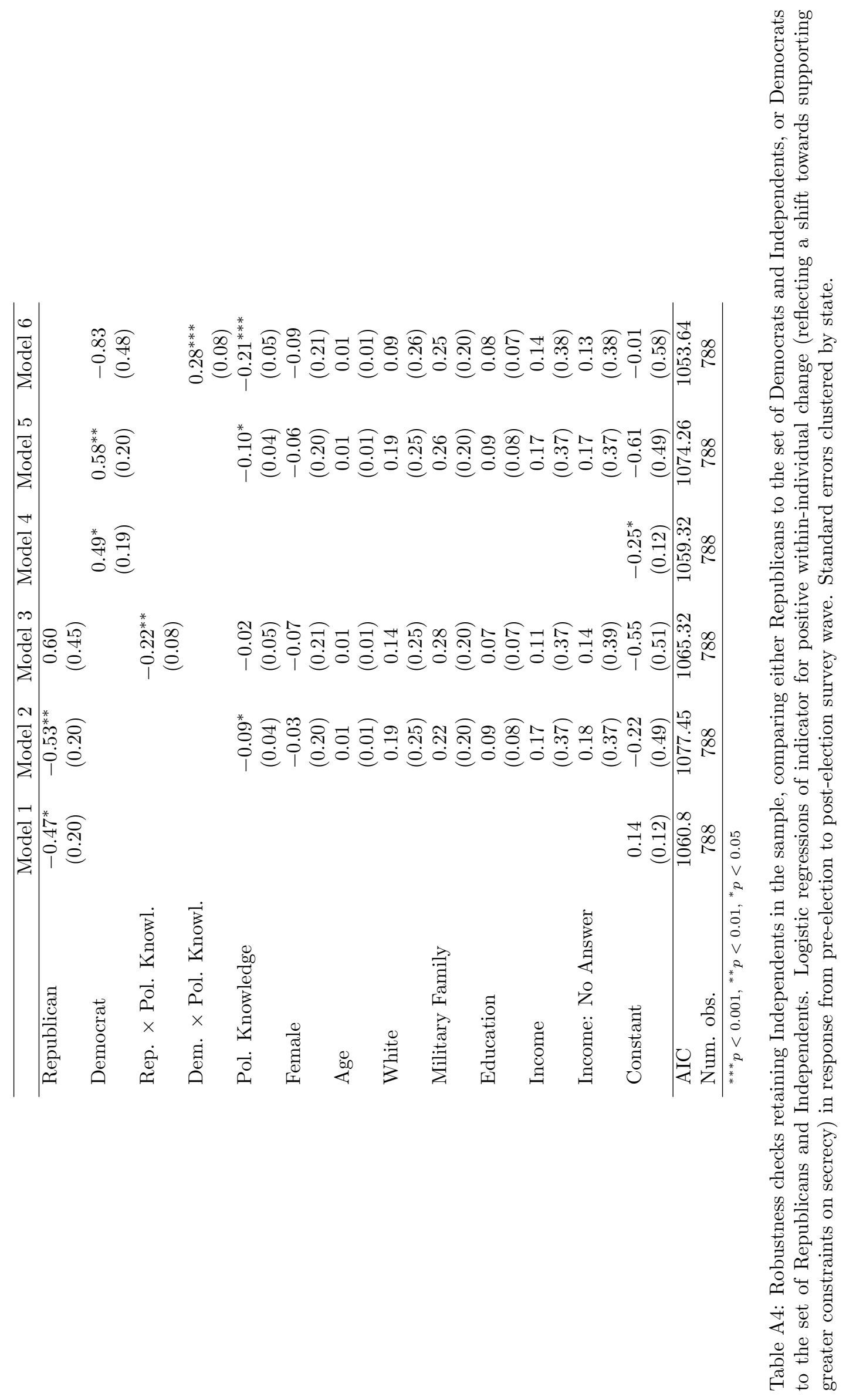




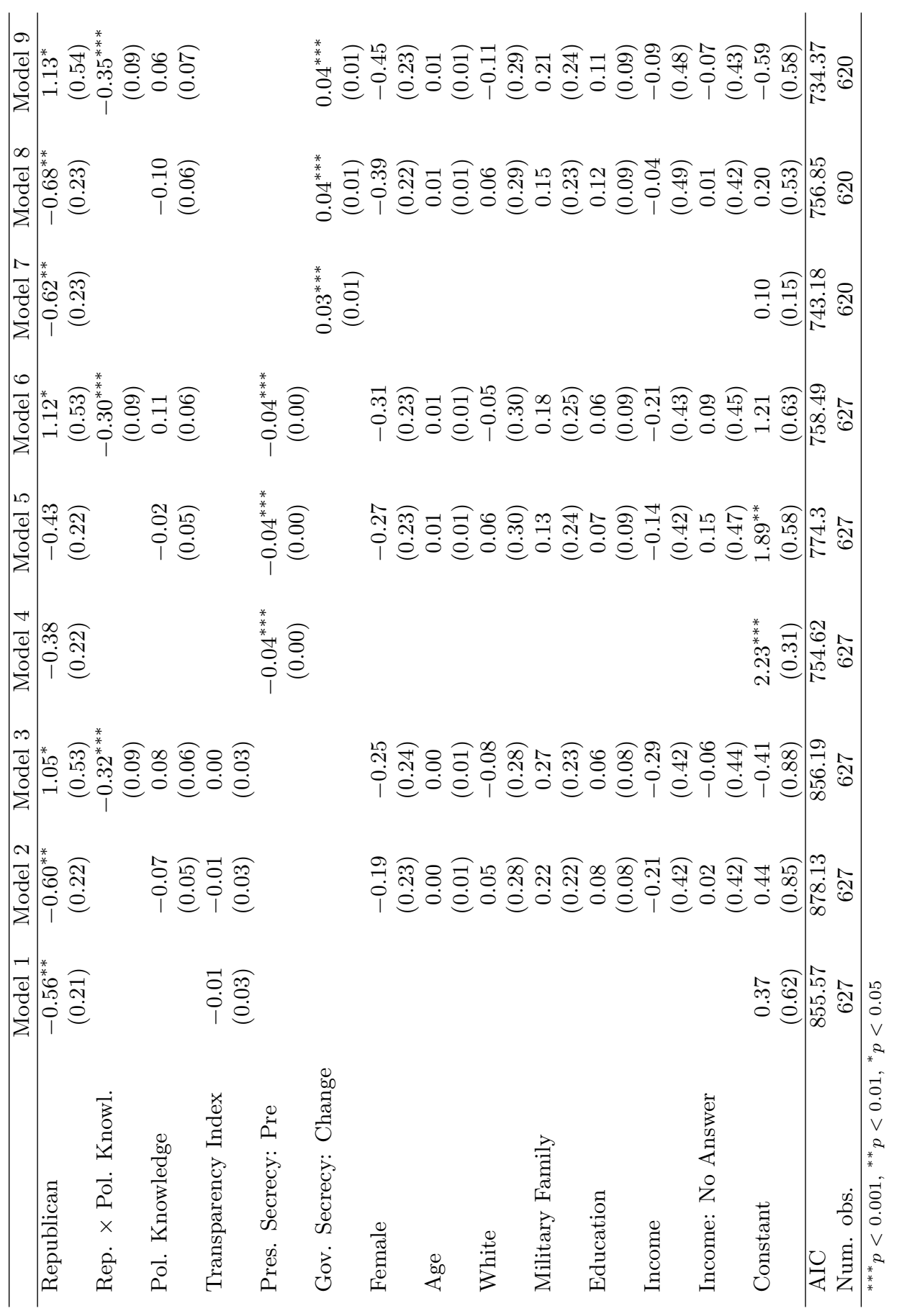

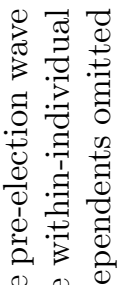

욤

. $\exists$ :

on

亏

要

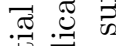

:.

它岁䔏

我总

प 0

궁 50

ठ․ำ

कि.

on 0

远

们

웡 옹

:

3 인

刍

苟

远苛

ฉ

के

¿

웡 ?

苛, 苟

茨艺 离

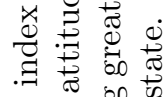

त $\infty$

40.0

寻芯

氞

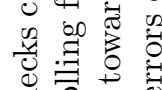

过

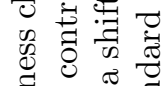

苟范

웅 च

수웜

$\ddot{4}+\underbrace{+}$

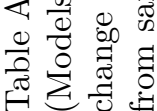




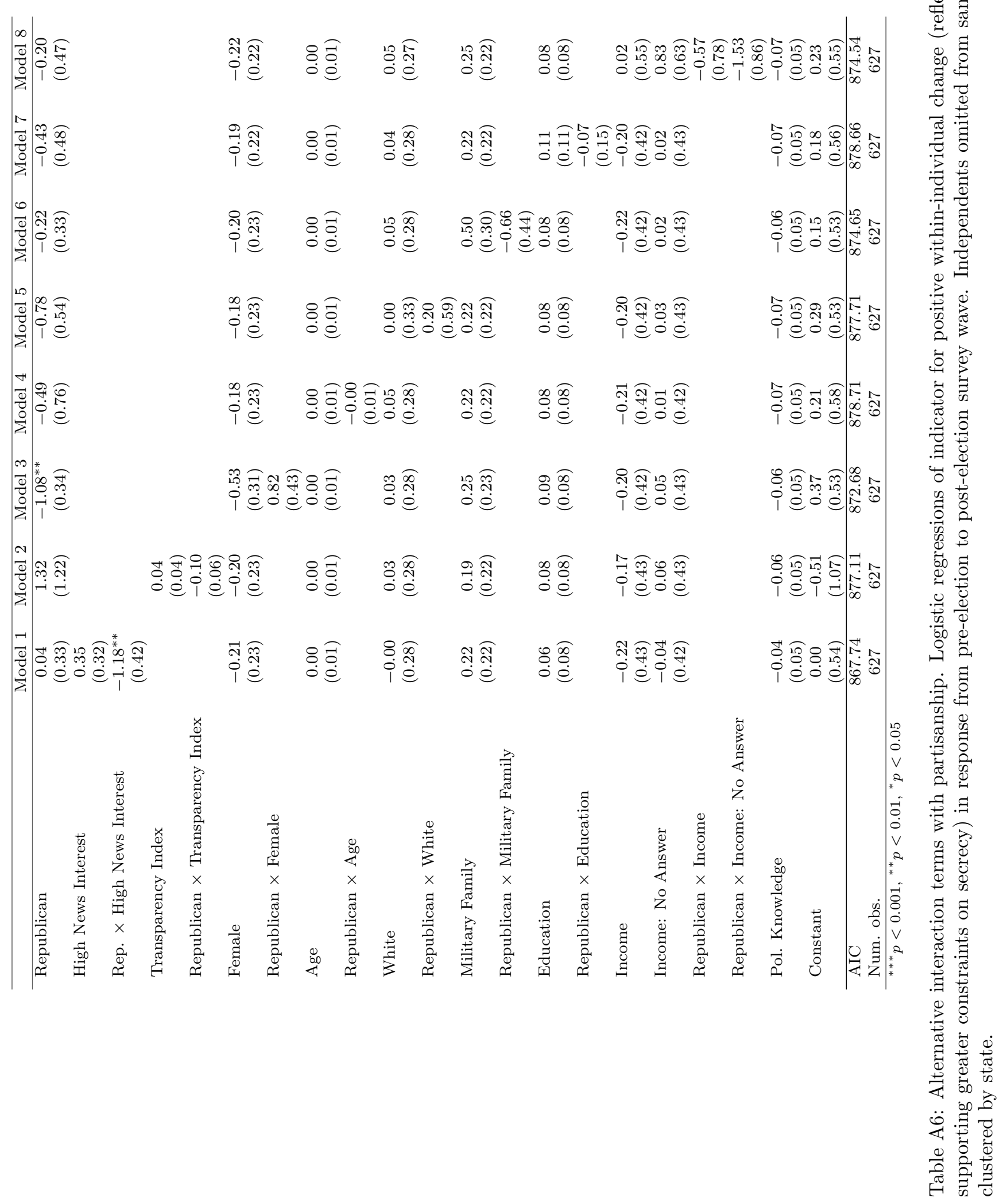




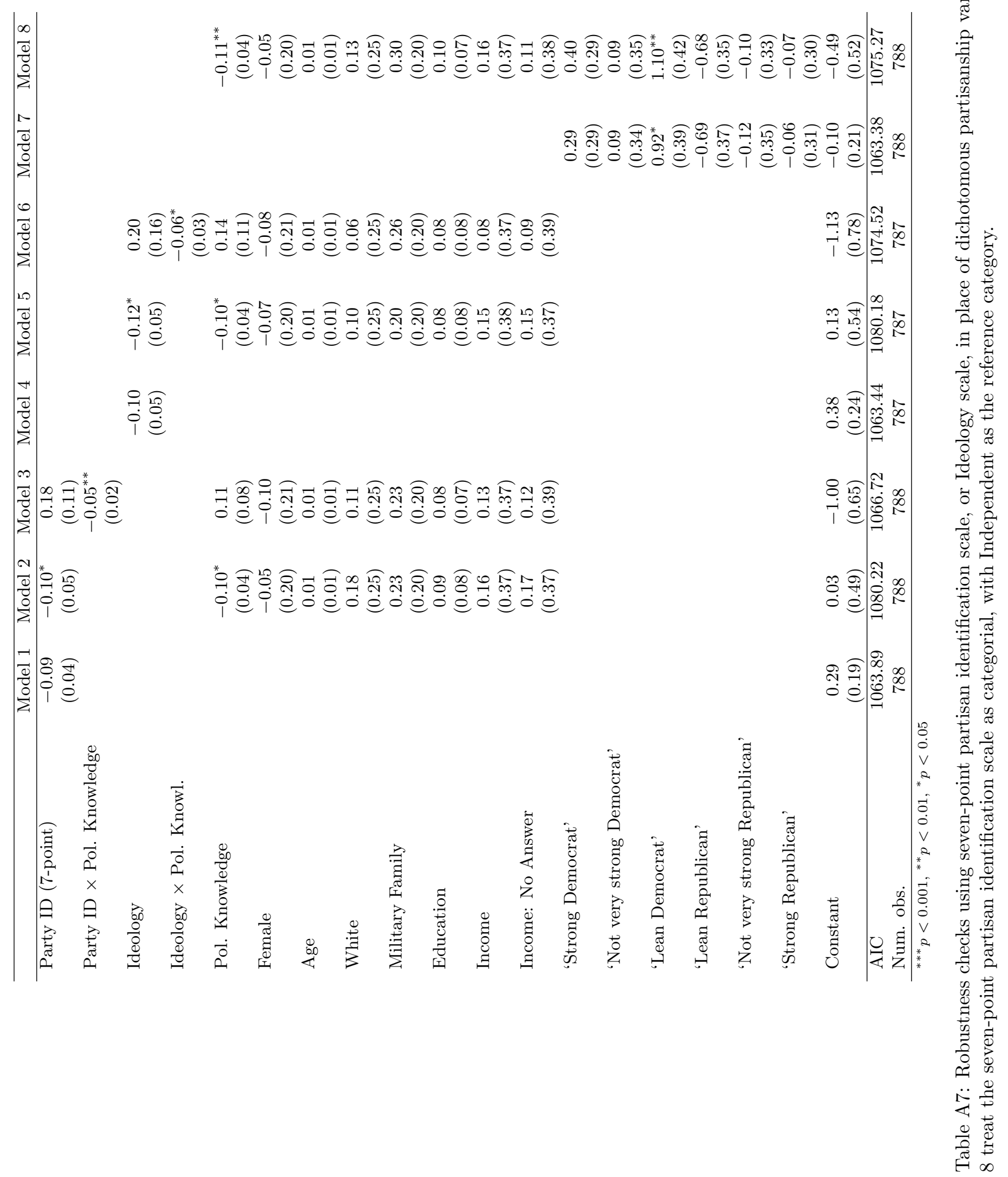




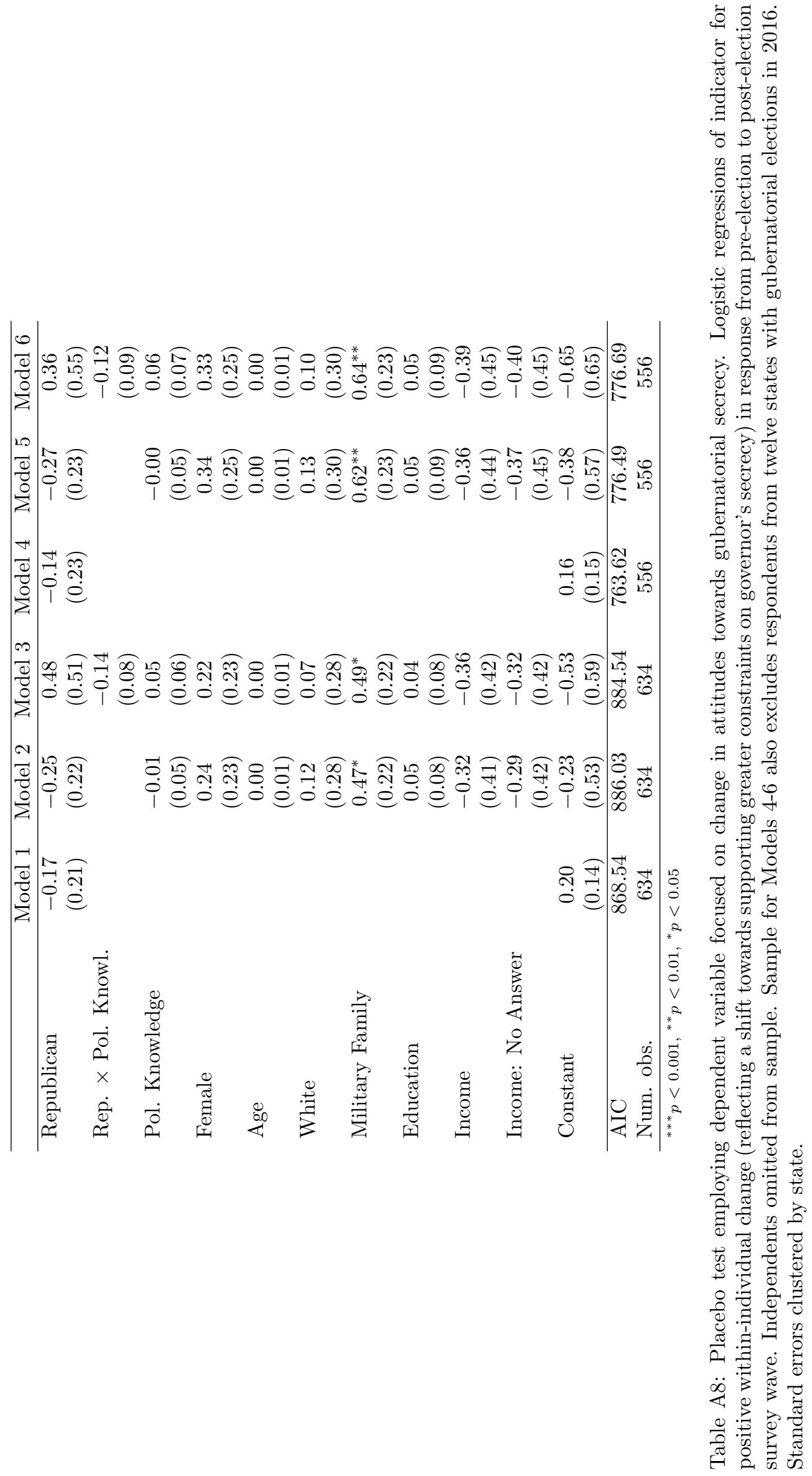

